\title{
Care-seeking behaviour and treatment
} practices for malaria in children under 5 years in Mozambique: a secondary analysis of 2011 DHS and 2015 IMASIDA datasets

\author{
Annette Cassy ${ }^{1,2^{*}} \mathbb{0}$, Abuchahama Saifodine ${ }^{3}$, Baltazar Candrinho ${ }^{4}$, Maria do Rosário Martins ${ }^{2}$,
} Saraiva da Cunha ${ }^{5}$, Filomena Martins Pereira ${ }^{2}$ and Eduardo Samo Gudo ${ }^{1}$

\begin{abstract}
Background: In Mozambique, the prevalence of malaria in children under 5 years of age is among the highest in the world, but limited data exist on determinants of care-seeking behaviour for malaria. This study aimed at determining the trends and factors associated with care-seeking behaviour for fever among children under 5 years of age and to assess the treatment practices for malaria.

Methods: Secondary data analysis of two cross-sectional studies. Descriptive statistics were used to summarize socio-economic and demographic characteristics of participants, using data from the 2011 Demographic and Health Survey and 2015 Indicators of Immunization, Malaria and HIV/AIDS Survey. Complex sampling logistic regression model was used to identify factors associated with care-seeking behaviour, with estimated adjusted odds ratio and respective 95\% confidence intervals, only for 2015 IMASIDA data.

Results: A total of 10,452 and 5168 children under 5 years of age were enrolled in the 2011 DHS and 2015 IMASIDA, respectively. Care-seeking for fever in public and private sectors remained stable during this period (62.6\%; 835/1432 in 2011 and 63.7\%; 974/1529 in 2015). The main place where care was sought in both surveys was public hospitals (86.2\%; 773/897 in 2011 and 86.7\%; 844/974 in 2015). Prescription of anti-malarial drugs increased from 42.9\% (385/897) in 2011 to 53.8\% (524/974) in 2015. Artemether-lumefantrine was the most used anti-malarial drug for febrile children in both surveys and its use increased from 59.0\% (219/373) in 2011 to 89.3\% (457/512) in 2015. Data from 2015 elucidated that care-seeking was more common in children whose mothers had a secondary level of education ( $\mathrm{AOR}=2.27$ [95\% Cl 1.15-4.49]) and among those in poorer quintile ( $\mathrm{AOR}=1.46$ [95\% Cl 0.83-1.90]). Mothers with higher education level $(A O R=0.16[95 \% \mathrm{Cl} 0.34-0.78])$ were less likely to seek out care. People from Manica $(A O R=2.49[1.03-6.01])$, Sofala $([A O R=2.91[1.03-8.24])$, Inhambane $(A O R=3.95[1.25-12.45])$, Gaza $(A O R=3.25$ [1.22-8.65]) and Maputo Province (AOR=2.65 [1.10-6.41]) were more likely to seek care than people from Maputo City.
\end{abstract}

Conclusion: Data from this study showed that care-seeking in Mozambique remained suboptimal. Interventions to raise the awareness for early care-seeking during episodes of fever should be urgently reinforced and intensified.

Keywords: Malaria, Care-seeking behavior, Treatment, Children under 5 years of age, Mozambique

\footnotetext{
*Correspondence: annnette.cassy@gmail.com

1 Program of Endemic Diseases of Large Impact, Instituto Nacional de

Saúde, Maputo, Mozambique

Full list of author information is available at the end of the article
} 


\section{Background}

Mozambique is ranked among the countries with high burden of malaria [1] and in 2016, accounted for $4 \%$ of all malaria cases and $4 \%$ of all malaria deaths worldwide [1]. The disease is the leading cause of morbidity and mortality in children under the age of 5 in the country [2]. In recent years, the number of reported cases of malaria in Mozambique in the public health services has increased and its prevalence in children under 5 years of age has remained stable at 38\% in 2011 and $40 \%$ in 2015 [3].

Early diagnosis and prompt and correct treatment are essential for a favourable malaria outcome, reducing its morbidity and mortality $[4,5]$. Thus, care-seeking behaviour for malaria remains a cornerstone for malaria control programs $[6,7]$.

There is limited data on malaria care-seeking in Mozambique and there are no published reports describing factors associated with malaria care-seeking behaviour in Mozambique. There is an urgent need to determine the patterns and factors associated with careseeking behaviour for malaria, as such knowledge is crucial for designing strategies aiming to improve malaria diagnosis and treatment [8-12]. In this context, this study was conducted with the following objectives: (i) analyse differences of care-seeking behaviour for fever in children under 5 years of age, using the 2011 Demographic and Health Survey (DHS) and 2015 Immunization, AIDS and Malaria Indicators Survey (IMASIDA) data and (ii) describe the factors associated with care-seeking behaviour and the treatment practices among children under 5 years of age, only using the 2015 IMASIDA data.

\section{Methods}

\section{Study design and data source}

This is a quantitative, observational study that analysed two national, cross-sectional studies in which data were collected in two periods of time: 2011 and 2015. A secondary data analysis using the 2011 DHS data and the 2015 IMASIDA data was conducted, to describe socioeconomic, demographic characteristics and treatment practices. The 2015 IMASIDA data was also used to identify factors associated with care-seeking behaviour. It was decided not to use the 2011 DHS data to identify the predictors of the care-seeking, because the data was collected long time ago and so that the situation may have changed and so it does not make much sense to identify these factors.

Both surveys used nationally representative samples. The 2011 DHS included 13,964 households distributed over 611 census enumeration areas (EAs) while 2015 IMASIDA included 7169 households distributed over 307 EAs. The response rate was $98.9 \%$ and $98 \%$ in 2011
DHS and 2015 IMASIDA, respectively. Methods for both surveys have been previously described $[3,13]$.

\section{Setting}

Both surveys were conducted in Mozambique. The country is located in the east coast of southern Africa and is divided in 11 provinces. Mozambique has a surface of approximately $799.380 \mathrm{~km}^{2}$ [14] and a population of 28.861.863 inhabitants [15]. The climate in Mozambique is tropical. The rainy season spans from October to March and the dry season occurs in the rest of the year [14]. There is year-round transmission of malaria with seasonal peaks during the rainy season. Data collection for 2011 DHS took place from June to November 2011 and for 2015 IMASIDA, from June to September 2015.

\section{Eligibility criteria}

This analysis used data from children aged from 0 to 59 months whose mothers or guardians were interviewed and provided information on the fever in the 2 weeks prior to the surveys.

\section{Measures}

The main outcome of this study is care-seeking behaviour of mothers/guardians of children under 5 years with history of fever in the 2 weeks prior to the survey. Potential covariates were identified for inclusion in a predictive model using literature review for "care-seeking" and "treatment-seeking" for fever and malaria. A total of 11 socioeconomic and demographic covariates previously shown to be associated with care-seeking [10, 16-24] were retrieved from 2015 IMASIDA dataset. The covariates included child's age, sex, place of residence (urban or rural), geographic region (provinces), religion (Catholic, Muslim, Protestant or other), household wealth quintile, mother's level of education, age and marital status (single, married/living with partner, divorced/separated or widowed), child's use of a bed net and whether the dwelling had been sprayed with insecticide within the last 12 months or not.

As there was no variable in the database that grouped all anti-malarials to compare, a variable group was created to group them together. Marital status was originally divided into six categories (single, married, living with partner, separated, divorced, widowed) and was decided to group in four categories (single, married/living with partner, divorced/separated and widowed). Religion was divided into eight categories and was regrouped into five categories including: the three most practiced religions in Mozambique (1) Catholic, (2) Islamic and (3) Protestant [25], the (4) category combined the remaining religions, and the (5) category as the non-religious. 


\section{Statistical analysis}

Data from 2011 DHS and 2015 IMASIDA were analysed using the same statistical methods. To prepare the data for analysis, the children (KR) and individual members $(\mathrm{PR})$ datasets were merged based on the unique identifier number (b16) for each survey, because the information about fever and care-seeking was available in KR file and information at a household level (use of bed net, indoor spraying) was available in the PR file.

Special (svy) survey commands were used to account for the complex multilevel survey design. Data were weighted to account for the differential selection probabilities at the EA, household, and individual levels so that any results with the regional weight factored into it would be representative at the national and regional level. Only weighted survey data are presented in this manuscript. Descriptive statistics were used to summarize socio-economic and demographic characteristics of participants, and comparison of care-seeking behaviours between categorical variables were assessed using Pearson Chi square test of independence. Complex sampling logistic regression model was used to identify factors associated with care-seeking behaviour, with estimated adjusted odds ratio (AOR) and respective $95 \%$ confidence intervals (CI), for 2015 IMASIDA data. All statistical analyses were performed using Stata, version 15 (Stata Corporation, College Station, Texas).

\section{Results}

\section{Socio-economic and demographic characteristics} of children with history of fever

As shown in Table 1, a total of 10,452 children under 5 years of age in 2011 DHS and 5168 children in 2015 IMASIDA were enrolled. The proportion of children with a history of fever doubled from $13.7 \%(1432 / 10,452)$ [95\% CI 12.6-14.9], in 2011 to $29.6 \%(1529 / 5128)$ [95\% CI 27.2-32.1], in 2015.

Fever was less common in children aged 0-6 months as compared to other age groups in both surveys, $(8.3 \%$ [95\% CI 6.5-10.5] in 2011 and 19.0\% [95\% CI 15.0-23.8] in 2015). In 2015, fever was more common in rural areas (31.9\% [95\% CI 28.8-35.1]) than in urban areas (20.3 [95\% CI 20.3-25.8]), but this difference was not observed in $2011(13.9 \%$ [95\% CI 12.6-15.3] in rural areas and 13.3\% [95\% CI 11.3-15.5] in urban areas). Missing data comprised less than $1 \%$.

\section{Care-seeking behaviour}

Care was sought for $62.6 \% \quad(835 / 1432 ; \quad[95 \%$ CI 59.0-66.1]), of the children with a history of fever in the 2 weeks prior to the survey in 2011 and $63.7 \%$ (974/1529; [95\% CI 59.3-67.8]), in 2015. Table 2 shows the demographic characteristics of children with fever for whom care was sought. In both 2011 DHS and 2015 IMASIDA, care-seeking had no significant difference between the age groups or gender.

In both surveys, care-seeking was higher in urban areas as compared to rural areas. In 2011, care-seeking was 75.0\% [95\% CI 69.8-79.7] in urban areas as compared to $58.2 \%$ [95\% CI 53.8-62.5] in rural areas. Similarly, in 2015 care-seeking was 74.9\% [95\% CI 68.4-80.4] in urban and $60.9 \%$ [95\% CI 55.6-65.9] in rural areas.

In 2011, Cabo Delgado province reported the lowest care-seeking (33.5\%), while in 2015, Zambézia province had the lowest care-seeking (58.6\%) reported. When comparing by region, the provinces situated in the southern region of the country presented the highest careseeking behaviour, excluding Maputo City (see Fig. 1). In term of wealth index, Table 2 shows that care-seeking was lower among those in the two lower quintiles. Missing data comprised less than $1 \%$.

Table 3 lists the places where care for fever was sought among participants of the 2011 DHS and the 2015 IMASIDA. In both surveys, care was sought mostly in public hospitals (86.2\%; 773/897 in 2011 DHS and 86.7\%; 844/974 in 2015 IMASIDA). Community health workers (CHW) were the second most common option for careseeking with little difference between years 2011 (5.2\%; 47/897) and 2015 (6.6\%; 64/974).

\section{Malaria treatment practices}

The frequency of children with fever who were treated with anti-malarial increased from $42.9 \%(385 / 897)$ in 2011 to $53.8 \%(524 / 974)$ in 2015 (Table 4). The most commonly used anti-malarial was artemether-lumefantrine and its frequency increased from 58.96\% (219/373) in 2011 to $89.34 \%$ (457/512) in 2015 (Table 4). The use of other anti-malarials, such as sulfadoxine-pyrimethamine, chloroquine and quinine, reduced from 2011 (21.2\%, $1.9 \%$ and $8.6 \%$, respectively) to 2015 (5.6\%, 0.3\% and $0.3 \%$, respectively).

\section{Predictors of care-seeking behaviour for fever}

Table 5 summarize the results of the multivariable analysis to identify factors associated with care-seeking behaviour for fever in 2015 IMASIDA.

Care-seeking for fever in 2015 was significantly more likely in children whose mothers had a secondary level of education, as compared to women with no education $(\mathrm{AOR}=2.27$ [95\% CI 1.15-4.49]), but women with higher education (beyond high school) were less likely to seek care $(\mathrm{AOR}=0.16$ [95\% CI 0.34-0.78]). People from the poorer quintile were more likely to seek care than people from the poorest (AOR $=1.46[95 \% \mathrm{CI}$ $0.83-1.90]$ ). People from rural areas were less likely to 
Table 1 Socio-economic and demographic characteristics of children under 5 years with history of fever-2011 DHS and 2015 IMASIDA

\begin{tabular}{|c|c|c|c|c|c|c|c|c|}
\hline \multirow[t]{2}{*}{ Characteristics } & \multicolumn{4}{|c|}{2011 DHS $(n=10,452)$} & \multicolumn{4}{|c|}{2015 IMASIDA $(n=5168)$} \\
\hline & $\mathrm{n}$ & Fever (\%) & $\begin{array}{l}\text { Lower } \\
\text { confidence }\end{array}$ & $\begin{array}{l}\text { Upper } \\
\text { confidence }\end{array}$ & $\mathrm{n}$ & Fever (\%) & $\begin{array}{l}\text { Lower } \\
\text { confidence }\end{array}$ & $\begin{array}{l}\text { Upper } \\
\text { confidence }\end{array}$ \\
\hline \multicolumn{9}{|l|}{ Child's age in months } \\
\hline$<6$ & 1176 & 8.3 & 6.5 & 10.5 & 532 & 19.0 & 15.0 & 23.8 \\
\hline $6-11$ & 1259 & 16.8 & 14.1 & 199 & 568 & 32.0 & 27.5 & 36.9 \\
\hline $12-23$ & 2285 & 17.2 & 15.0 & 19.7 & 1116 & 35.3 & 30.9 & 40.0 \\
\hline $24-35$ & 1945 & 15.3 & 13.4 & 17.4 & 1003 & 32.4 & 28.7 & 36.4 \\
\hline $36-47$ & 1989 & 11.9 & 10.2 & 13.8 & 1019 & 28.9 & 25.0 & 33.0 \\
\hline $48-59$ & 1771 & 10.9 & 8.9 & 13.2 & 905 & 24.8 & 21.0 & 29.0 \\
\hline Missing data & 27 & $0.3 \%$ & & & 25 & $0.5 \%$ & & \\
\hline \multicolumn{9}{|l|}{ Sex of child } \\
\hline Male & 5257 & 14.0 & 12.6 & 15.4 & 2563 & 30.1 & 27.3 & 33.0 \\
\hline Female & 5195 & 13.4 & 12.0 & 15.0 & 2605 & 29.1 & 26.1 & 32.3 \\
\hline \multicolumn{9}{|l|}{ Place of residence } \\
\hline Urban & 2840 & 13.3 & 11.3 & 15.5 & 1330 & 23.0 & 20.3 & 25.8 \\
\hline Rural & 7612 & 13.9 & 12.6 & 15.3 & 3838 & 31.9 & 28.8 & 35.1 \\
\hline \multicolumn{9}{|l|}{ Region } \\
\hline \multicolumn{9}{|l|}{ Northern } \\
\hline Niassa & 641 & 11.7 & 9.0 & 14.9 & 351 & 30.3 & 23.3 & 38.3 \\
\hline Cabo Delgado & 885 & 15.3 & 12.6 & 18.4 & 466 & 21.8 & 15.6 & 29.7 \\
\hline Nampula & 1581 & 13.3 & 10.4 & 16.2 & 1154 & 39.8 & 33.4 & 46.5 \\
\hline \multicolumn{9}{|l|}{ Central } \\
\hline Zambézia & 2188 & 16.6 & 13.1 & 20.7 & 722 & 52.0 & 46.1 & 57.8 \\
\hline Tete & 1356 & 12.9 & 10.2 & 16.1 & 448 & 14.5 & 12.0 & 17.4 \\
\hline Manica & 766 & 12.9 & 10.2 & 16.1 & 429 & 16.8 & 12.7 & 21.8 \\
\hline Sofala & 1036 & 16.5 & 13.5 & 19.9 & 522 & 21.0 & 17.4 & 25.2 \\
\hline \multicolumn{9}{|l|}{ Southern } \\
\hline Inhambane & 557 & 8.9 & 6.5 & 12.1 & 284 & 18.2 & 12.1 & 26.4 \\
\hline Gaza & 541 & 11.1 & 8.8 & 13.9 & 409 & 27.6 & 23.4 & 33.2 \\
\hline Maputo Province & 554 & 10.5 & 8.2 & 13.3 & 209 & 15.4 & 11.2 & 20.8 \\
\hline Maputo City & 348 & 11.0 & 8.5 & 14.1 & 175 & 24.6 & 18.8 & 31.4 \\
\hline \multicolumn{9}{|l|}{ Wealth index } \\
\hline Poorest & 2478 & 14.3 & 12.1 & 16.9 & 1212 & 32.8 & 28.8 & 37.1 \\
\hline Poorer & 2278 & 14.9 & 12.8 & 17.2 & 1177 & 33.6 & 28.5 & 39.1 \\
\hline Middle & 2096 & 13.5 & 11.8 & 15.5 & 1072 & 30.1 & 26.0 & 34.5 \\
\hline Richer & 2069 & 12.7 & 10.6 & 15.1 & 956 & 26.9 & 23.3 & 30.9 \\
\hline Richest & 1530 & 12.6 & 10.7 & 14.9 & 751 & 20.7 & 17.9 & 23.7 \\
\hline Total & 10,452 & 13.7 & 12.6 & 14.9 & 5168 & 29.6 & 27.2 & 32.1 \\
\hline
\end{tabular}

seek care than people from urban areas $(\mathrm{AOR}=0.58$ [0.34-1.00]). In relation to provinces, people from Manica $(\mathrm{AOR}=2.49[1.03-6.01])$, Sofala $([\mathrm{AOR}=2.91$ $[1.03-8.24])$, Inhambane $(\mathrm{AOR}=3.95[1.25-12.45])$, Gaza $(\mathrm{AOR}=3.25[1.22-8.65])$ and Maputo Province $(\mathrm{AOR}=2.65[1.10-6.41])$ were more likely to seek care than people from Maputo City. Missing data comprised less than $2 \%$.

\section{Discussion}

This is the first study describing factors associated with care-seeking behaviour for fever in Mozambique. In this study the pattern of care-seeking for fever and its predictors among children under 5 years of age were investigated. The study data showed that despite the fact that the percentage of children with fever doubled from $13.7 \%$ in 2011 DHS to $27.2 \%$ in 2015 IMASIDA, 
Table 2 Socio-economic and demographic characteristics of children under 5 years for whom care was sought-2011 DHS and 2015 IMASIDA

\begin{tabular}{|c|c|c|c|c|c|c|c|c|}
\hline \multirow[t]{2}{*}{ Characteristics } & \multicolumn{4}{|c|}{2011 DHS $(n=1432)$} & \multicolumn{4}{|c|}{2015 IMASIDA $(n=1529)$} \\
\hline & $\mathrm{n}$ & Sought care (\%) & $\begin{array}{l}\text { Lower } \\
\text { confidence }\end{array}$ & $\begin{array}{l}\text { Upper } \\
\text { confidence }\end{array}$ & $n$ & Sought care (\%) & $\begin{array}{l}\text { Lower } \\
\text { confidence }\end{array}$ & $\begin{array}{l}\text { Upper } \\
\text { confidence }\end{array}$ \\
\hline \multicolumn{9}{|l|}{ Child's age in months } \\
\hline$<6$ & 97 & 63.9 & 52.7 & 73.7 & 101 & 67.5 & 56.1 & 77.1 \\
\hline $6-11$ & 212 & 71.7 & 63.2 & 78.9 & 182 & 67.1 & 58.3 & 74.8 \\
\hline $12-23$ & 394 & 61.4 & 54.9 & 67.4 & 394 & 63.4 & 57.1 & 69.2 \\
\hline $24-35$ & 298 & 59.5 & 52.5 & 66.2 & 325 & 65.1 & 57.4 & 72.0 \\
\hline $36-47$ & 237 & 62.2 & 53.8 & 70.0 & 294 & 62.0 & 53.9 & 69.5 \\
\hline $48-59$ & 193 & 60.2 & 50.1 & 69.5 & 224 & 59.4 & 50.2 & 68.0 \\
\hline Missing data & 1 & $0.1 \%$ & & & 9 & $0.6 \%$ & & \\
\hline \multicolumn{9}{|l|}{ Sex of child } \\
\hline Male & 734 & 61.3 & 56.6 & 65.9 & 771 & 62.6 & 56.6 & 68.3 \\
\hline Female & 699 & 64.0 & 59.4 & 68.3 & 758 & 64.7 & 59.5 & 69.7 \\
\hline \multicolumn{9}{|l|}{ Place of residence } \\
\hline Urban & 377 & 75.0 & 69.8 & 79.7 & 305 & 74.9 & 68.4 & 80.4 \\
\hline Rural & 1055 & 58.2 & 53.8 & 62.5 & 1224 & 60.9 & 55.6 & 65.9 \\
\hline \multicolumn{9}{|l|}{ Region } \\
\hline \multicolumn{9}{|l|}{ Northern } \\
\hline Niassa & 75 & 52.2 & 39.4 & 64.8 & 106 & 51.7 & 42.4 & 60.9 \\
\hline Cabo Delgado & 135 & 33.5 & 24.4 & 44.1 & 102 & 62.2 & 52.2 & 71.3 \\
\hline Nampula & 210 & 86.2 & 75.0 & 92.8 & 459 & 64.2 & 53.9 & 73.4 \\
\hline \multicolumn{9}{|l|}{ Central } \\
\hline Zambézia & 362 & 56.6 & 49.4 & 63.5 & 37 & 58.5 & 48.2 & 68.0 \\
\hline Tete & 175 & 54.4 & 43.5 & 64.8 & 65 & 63.7 & 41.3 & 81.3 \\
\hline Manica & 99 & 59.3 & 45.3 & 71.9 & 72 & 68.3 & 59.6 & 75.9 \\
\hline Sofala & 170 & 76.7 & 68.7 & 83.2 & 110 & 69.9 & 58.1 & 79.6 \\
\hline \multicolumn{9}{|l|}{ Southern } \\
\hline Inhambane & 49 & 65.8 & 53.2 & 76.5 & 52 & 77.8 & 64.4 & 87.1 \\
\hline Gaza & 60 & 71.4 & 62.0 & 79.3 & 113 & 73.5 & 61.8 & 82.7 \\
\hline Maputo Province & 58 & 68.9 & 57.7 & 78.2 & 32 & 76.7 & 63.6 & 86.2 \\
\hline Maputo City & 38 & 69.3 & 54.8 & 80.8 & 43 & 60.2 & 45.8 & 73.0 \\
\hline \multicolumn{9}{|l|}{ Wealth index } \\
\hline Poorest & 355 & 56.8 & 49.0 & 64.3 & 398 & 53.9 & 46.0 & 61.7 \\
\hline Poorer & 338 & 49.6 & 41.9 & 57.3 & 395 & 63.7 & 54.8 & 71.8 \\
\hline Middle & 284 & 66.4 & 60.2 & 72.0 & 323 & 63.3 & 56.3 & 69.7 \\
\hline Richer & 262 & 76.2 & 70.6 & 81.0 & 257 & 73.8 & 67.2 & 79.5 \\
\hline Richest & 194 & 72.2 & 64.0 & 79.2 & 155 & 72.7 & 64.4 & 79.6 \\
\hline Total & 1432 & 62.6 & 59.0 & 66.1 & 1529 & 63.7 & 59.3 & 67.8 \\
\hline
\end{tabular}

care-seeking remained stable at $63 \%$ in this period. This figure is lower than the 70\% defined by Mozambique's National Malaria Control Program [26]. This finding is alarming, given that malaria is a major cause of fever in children in Mozambique and prompt care-seeking is necessary to reduce morbidity and mortality [3]. These data suggest that social and behaviour change communication directed to improving care-seeking efforts should be intensified.

The percentage of children for whom care was not sought, found in both surveys, was similar to what was reported in a study conducted in Senegal, in which 37\% of children with fever did not receive any treatment or medical advice [27]. However, this figure is higher than 
MALARIA PREVALENCE AND CARE-SEEKING BY PROVINCE IN 2015

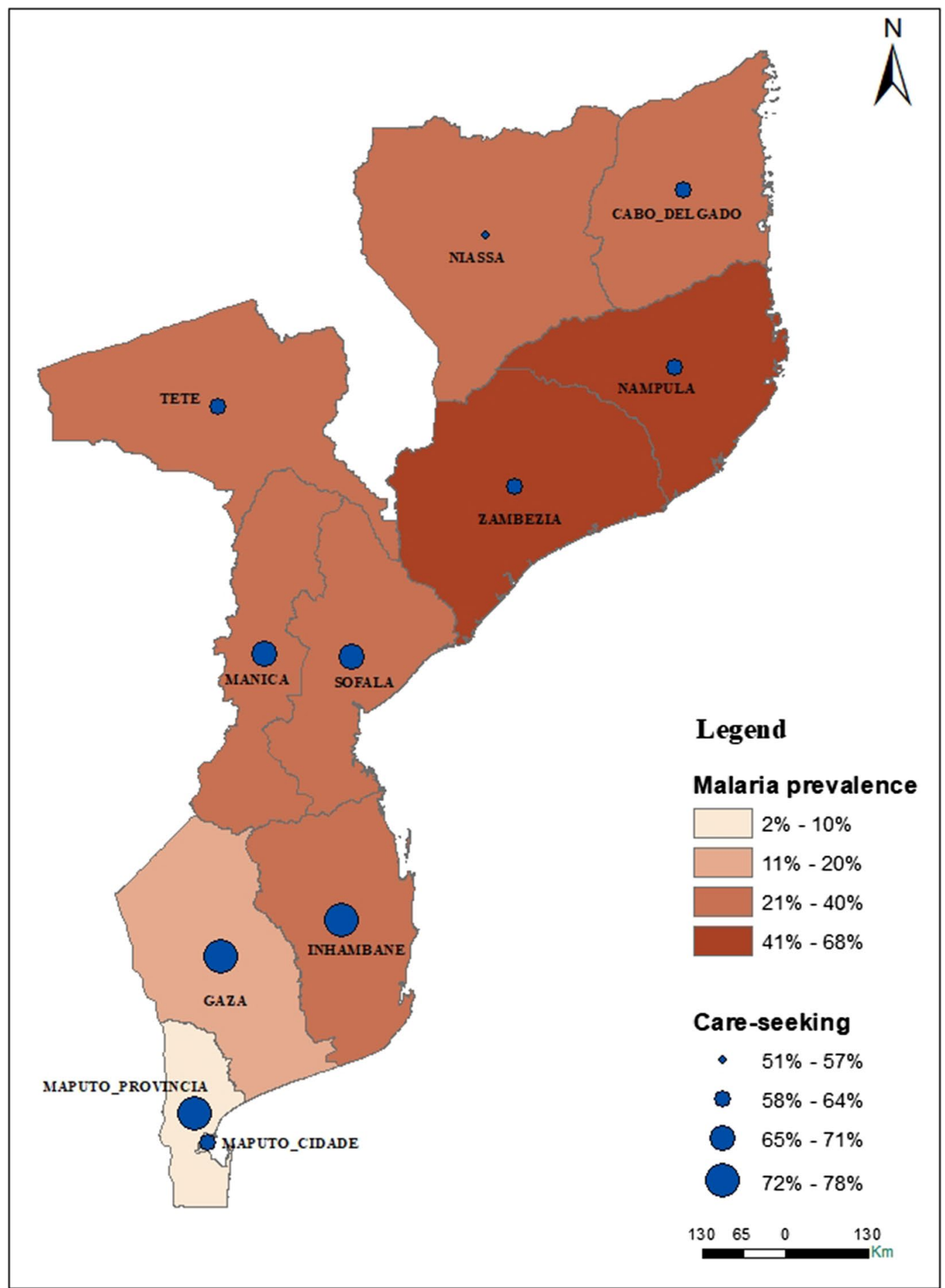

Fig. 1 Malaria prevalence and care-seeking for fever in 2015 
Table 3 Place care first sought for children under five with fever-2011 DHS and 2015 IMASIDA

\begin{tabular}{lll}
\hline Place & $\mathbf{n}(\%)$ \\
\cline { 2 - 3 } & $\mathbf{2 0 1 1}$ & $\mathbf{2 0 1 5}$ \\
\hline Public hospital & $773(86.2)$ & $844(86.7)$ \\
Community health worker & $47(5.2)$ & $64(6.6)$ \\
Other public services & $10(1.1)$ & $12(1.2)$ \\
Private services & $10(1.1)$ & $23(2.4)$ \\
Traditional healer and informal market & $28(3.1)$ & $11(1.1)$ \\
Informal market & $21(2.3)$ & $12(1.2)$ \\
Other & $8(0.9)$ & $7(0.8)$ \\
Total & 897 & 974 \\
\hline
\end{tabular}

Table 4 Type of anti-malarial taken for fever-2011 DHS and 2015 IMASIDA

\begin{tabular}{lll}
\hline Type of anti-malarial & $\mathbf{n}(\%)$ & \\
\cline { 2 - 3 } & $\mathbf{2 0 1 1}$ & $\mathbf{2 0 1 5}$ \\
\hline Sulfadoxine-pyrimethamine & $81(21.2)$ & $29(5.6)$ \\
Chloroquine & $7(1.9)$ & $2(0.3)$ \\
Amodiaquine & $9(2.3)$ & $1(0.2)$ \\
Quinine & $33(8.6)$ & $2(0.3)$ \\
Artemisinin combination & $8(2.0)$ & $8(1.6)$ \\
Artemether-lumefantrine & $229(59.5)$ & $461(88.0)$ \\
Other & $18(4.6)$ & $21(3.9)$ \\
Total & 385 & 524 \\
\hline
\end{tabular}

what was reported in a study in Nigeria where care was not sought for $23 \%$ of the children [28]. The study carried out in Senegal showed that short duration of fever and rapid recovery from the disease were associated with not seeking care for fever [27]. However, in both 2011 DHS and 2015 IMASIDA, the duration of fever and severity of the disease were not documented and for this reason, any assumption on the relationship between care-seeking and the duration and severity of the febrile illness can't be made.

This results clearly demonstrate important differences in care-seeking for fever by geographic region. Of note, Zambézia which is the province with highest malaria prevalence in the country and the second most populous province in the country, had one of the lowest reported care-seeking behaviours for fever. This low care-seeking in Zambézia has previously been found in a study on care-seeking behaviour for any disease or wound in any age [29]. The report also showed that the satisfaction with health services in the province of Zambézia was the lowest, compared to all other provinces in the country (44.5\%) [29]. These findings may indicate that patient satisfaction with health services plays an important role on care-seeking behavioural outcome. Thus, Zambézia province may need further investments, not only in malaria control interventions but also in the quality of services provided in order to improve care-seeking for fever.

Higher care-seeking rates in the southern region of Mozambique might partially be related to the fact that literacy and access to medical services in the southern region is also higher [29]. This suggests that investments in social determinants of health and health systems pillars should also be considered in order to improve careseeking for fever. Yet, despite having the highest access to health facilities (96.4\%) [29], Maputo City has low care-seeking for fever. This might be associated with self-medication.

In Mozambique care for fever was mostly sought at public hospitals. This finding is different from Zambia where most of the caretakers sought treatment of fever for their children from $\mathrm{CHW}$, friends, relatives, traditional healers or spiritualists [30], and from India, where traditional healers were the first choice [22]. This preference for public services should continue to be reinforced as the standard of care for diagnostic and treatment in public health facilities is good and malaria tests and treatments are provided for free. Although the $\mathrm{CHW}$ were the second place where care was most sought, and it did not increase significantly from 2011 to 2015, and was less frequent than what was reported in Zambia [30] and in India [31]. The fact that the proportion of people seeking care from CHWs remained almost stable from 2011 to $2015,5.2 \%$ and $6.6 \%$, respectively, is a surprising and concerning finding. For instance, in 2010 the Ministry of Health $(\mathrm{MoH})$ started a process of expanding and improving its $\mathrm{CHW}$ programme, and the number of trained CHWs increased significantly during the period of the two surveys [32]. These suggests that more work is needed to improve utilization of the services provided by CHWs.

Data from 2015 IMASIDA showed that mother's education was positively associated with care-seeking behaviour, as has been shown in other studies [17, 23, 33]. Mothers with secondary level of education were more likely to seek care than mothers with a lower education level. This lower care-seeking behaviour for fever among mother's with low level of education can be explained by their lower awareness about etiology, prevention, diagnostics, treatment and complications of malaria [17, 33]. Despite evidence that care-seeking has been positively associated with knowledge and awareness [17], results from this study showed that mothers with the highest level of education were less likely to seek care. It is possible that because highly educated mothers have grater health literacy they rely more on self-treatment. These results also show that the association between mother's 
Table 5 Logistic regression analysis of factor associated with malaria care-seeking behaviour for children under five with fever, 2015 IMASIDA

\begin{tabular}{|c|c|c|c|c|c|c|}
\hline \multirow[t]{2}{*}{ Variable } & \multicolumn{3}{|c|}{ Univariable analysis } & \multicolumn{3}{|c|}{ Multivariable analysis } \\
\hline & OR & $(95 \% \mathrm{Cl})$ & p-value & OR & $(95 \% \mathrm{Cl})$ & p-value \\
\hline \multicolumn{7}{|l|}{ Child's age in months } \\
\hline$<6$ & 1 & & Reference & 1 & & Reference \\
\hline $06-11$ & 0.98 & $(0.55-1.75)$ & 0.954 & 0.95 & $(0.52-1.76)$ & 0.873 \\
\hline $12-23$ & 0.83 & $(0.51-1.38)$ & 0.477 & 0.88 & $(0.52-1.49)$ & 0.637 \\
\hline $24-35$ & 0.90 & $(0.52-1.56)$ & 0.700 & 0.98 & $(0.55-1.75)$ & 0.946 \\
\hline $36-47$ & 0.79 & $(0.46-1.36)$ & 0.388 & 0.90 & $(0.52-1.56)$ & 0.700 \\
\hline $48-59$ & 0.71 & $(0.41-1.21)$ & 0.209 & 0.84 & $(0.47-1.50)$ & 0.558 \\
\hline Missing data & 8 & $0.5 \%$ & & & & \\
\hline \multicolumn{7}{|l|}{ Sex of child } \\
\hline Male & 1 & & Reference & 1 & & Reference \\
\hline Female & 1.10 & $(0.81-1.47)$ & 0.543 & 1.13 & $(0.83-1.53)$ & 0.442 \\
\hline \multicolumn{7}{|l|}{ Type of place of residence } \\
\hline Urban & 1 & & Reference & 1 & & Reference \\
\hline Rural & 0.52 & $(0.36-0.77)$ & 0.001 & 0.65 & $(0.40-1.10)$ & 0.081 \\
\hline \multicolumn{7}{|l|}{ Region } \\
\hline North & 1 & & Reference & 1 & & Reference \\
\hline Center & 1.01 & $(0.67-1.53)$ & 0.963 & 0.94 & $(0.53-1.67)$ & 0.832 \\
\hline South & 1.62 & $(1.04-2.52)$ & 0.033 & 1.18 & $(0.61-2.31)$ & 0.622 \\
\hline \multicolumn{7}{|l|}{ Wealth index } \\
\hline Poorest & 1 & & Reference & 1 & & Reference \\
\hline Poorer & 1.5 & $(1.02-2.20)$ & 0.04 & 1.47 & $(1.02-2.13)$ & 0.039 \\
\hline Middle & 1.47 & $(0.95-2.27)$ & 0.081 & 1.38 & $(0.91-2.08)$ & 0.127 \\
\hline Richer & 2.40 & $(1.60-3.61)$ & 0 & 1.57 & $(0.95-2.59)$ & 0.075 \\
\hline Richest & 2.27 & $(1.38-3.72)$ & 0.001 & 0.93 & $(0.47-1.89)$ & 0.850 \\
\hline \multicolumn{7}{|l|}{ Religion } \\
\hline Catholic & 1 & & Reference & 1 & & Reference \\
\hline Islamic & 0.92 & $(0.62-1.37)$ & 0.694 & 0.81 & $(0.53-1.26)$ & 0.354 \\
\hline Protestant & 0.96 & $(0.61-1.51)$ & 0.851 & 0.87 & $(0.49-1.54)$ & 0.625 \\
\hline Others & 1.43 & $(0.91-2.25)$ & 0.121 & 1.20 & $(0.72-2.02)$ & 0.478 \\
\hline No religion & 0.59 & $(0.32-1.09)$ & 0.09 & 0.66 & $(0.32-1.40)$ & 0.279 \\
\hline \multicolumn{7}{|l|}{ Mother's age } \\
\hline $15-24$ & 1 & & Reference & 1 & & Reference \\
\hline $25-34$ & 0.67 & $(0.48-0.95)$ & 0.023 & 0.77 & $(0.52-1.13)$ & 0.183 \\
\hline $35-49$ & 0.52 & $(0.36-0.75)$ & 0 & 0.65 & $(0.43-0.97)$ & 0.034 \\
\hline \multicolumn{7}{|l|}{ Mothers' current marital status } \\
\hline Single/never married & 1 & & Reference & 1 & & Reference \\
\hline Married/living with partner & 0.39 & $(0.20-0.74)$ & 0.004 & 0.65 & $(0.33-1.29)$ & 0.215 \\
\hline Widowed & 0.43 & $(0.15-1.23)$ & 0.114 & 0.68 & $(0.19-2.41)$ & 0.553 \\
\hline Divorced/separated & 0.38 & $(0.19-0.79)$ & 0.010 & 0.62 & $(0.29-1.34)$ & 0.223 \\
\hline \multicolumn{7}{|c|}{ Mother's highest educational level } \\
\hline No education & 1 & & Reference & 1 & & Reference \\
\hline Primary & 1.6 & $(1.16-2.21)$ & 0.004 & 1.3 & $(0.91-1.86)$ & 0.142 \\
\hline Secondary & 4.02 & $(2.32-6.98)$ & 0.000 & 2.32 & $(1.18-4.56)$ & 0.015 \\
\hline Higher & 0.26 & $(0.06-1.06)$ & 0.060 & 0.17 & $(0.04-0.76)$ & 0.021 \\
\hline Missing data & 9 & $0.6 \%$ & & & & \\
\hline
\end{tabular}


Table 5 (continued)

\begin{tabular}{|c|c|c|c|c|c|c|}
\hline \multirow[t]{2}{*}{ Variable } & \multicolumn{3}{|c|}{ Univariable analysis } & \multicolumn{3}{|c|}{ Multivariable analysis } \\
\hline & OR & $(95 \% \mathrm{Cl})$ & p-value & OR & $(95 \% \mathrm{Cl})$ & p-value \\
\hline \multicolumn{7}{|l|}{ Use of bed net } \\
\hline No & 1 & & Reference & 1 & & Reference \\
\hline Yes & 1.15 & $(0.85-1.55)$ & 0.38 & 1.02 & $(0.75-1.39)$ & 0.892 \\
\hline \multicolumn{7}{|c|}{ Has dwelling been sprayed } \\
\hline No & 1 & & Reference & 1 & & Reference \\
\hline Yes & 1.01 & $(0.67-1.53)$ & 0.948 & 0.88 & $(0.55-1.41)$ & 0.600 \\
\hline Missing data (total) & & & & 30 & $1.96 \%$ & \\
\hline
\end{tabular}

education and care-seeking behaviour is complex. In fact, some studies failed to find any association between mother's education and care-seeking behaviour for fever [10].

Care-seeking behaviour for fever was also associated with place of residence. Caretakers from rural areas were less likely to seek care for febrile children than those from urban areas. Similar findings have been reported in previous studies conducted in other sub Saharan Africa countries [16, 19, 34]. This was an expected finding as access to care is known to be lower in rural areas of Mozambique as compared to urban areas and people living in rural area usually travel long distances to reach health facilities [14].

Wealth of the caregiver was also associated with careseeking behaviour for fever, a finding similar to other settings [17, 24]. Caretakers from the poorer quintile were more likely to seek care than the caretakers from the poorest quintile. This difference can be explained by lower access to health services among caregivers from the poorest quintile, as described in other settings [35].

Despite the better access and conditions found in Maputo City, care-seeking was higher in other provinces like Manica, Sofala, Inhambane, Gaza and Maputo province than in Maputo City, which might be not only associated with the self-medication mentioned before but also to the fact that the interventions to raise awareness for early care-seeking are implemented by the CHW and Maputo City is the only province in Mozambique without CHW Program [32]. Care-seeking behaviour was not influenced by child's age or sex, a finding similar to other studies carried out in Ethiopia and Zambia [10, 30].

This study had two important limitations. First, the data related to fever and treatment practices by caretakers was self-reported. It is possible that some participants have had difficulties in recalling all relevant details or may have been influenced by social-desirability bias. However, given that only episodes of fever in the 2 weeks prior to the surveys were considered, this may have contributed to minimize the recall bias. Secondly, although both surveys used nationally and regionally representative samples, their sample sizes were different.

\section{Conclusion}

This study showed that care-seeking for fever in children under 5 in Mozambique remained sub optimal from 2011 to 2015. This low care-seeking placed febrile children with malaria infection at serious risks of progression to severe malaria disease and death due to lack of or delayed treatment. This study highlights that interventions to raise awareness for early care-seeking during episodes of fever, along with interventions to increase community awareness about malaria treatment particularly in Zambézia Province, should be urgently reinforced and intensified in order to save lives and control the epidemic.

\section{Abbreviations}

AIDS: Acquired Immunodeficiency Syndrome; AOR: Adjusted odds ratio; Cl: Confidence intervals; CHW: Community Health Workers; DHS: Demographic and Health Survey; EA: Enumeration Area; HIV: Human Immunodeficiency Virus; IMASIDA: Indicators of Immunization, Malaria and HIV/AIDS Survey (Inquérito de Indicadores de Imunização, Malária e HIV/SIDA in portuguese); $\mathrm{MoH}$ : Ministry of Health.

\section{Authors' contributions}

$A C, A S$ and ESG designed the study and performed data analysis. MRM revised the data analysis. AC, AS, ESG, BC, MRM, SC and FP drafted the manuscript. All authors read and approved the final manuscript.

\section{Author details}

${ }^{1}$ Program of Endemic Diseases of Large Impact, Instituto Nacional de Saúde, Maputo, Mozambique. ${ }^{2}$ Global Health and Tropical Medicine, Instituto de Higiene e Medicina Tropical, Universidade Nova de Lisboa, Lisbon, Portugal.

${ }^{3}$ President's Malaria Initiative, USAID, Maputo, Mozambique. ${ }^{4}$ National Malaria Control Program, National Directorate of Public Health, Ministry of Health, Maputo, Mozambique. ${ }^{5}$ Faculty of Medicine, University of Coimbra, Coimbra, Portugal.

\section{Acknowledgements}

We would like to thank Cameron Taylor and Joy Fishel for all their support in the DHS data analysis and Anne McIntyre, Steve McCracken and Rose Zulliger for revising the manuscript.

\section{Competing interests}

The authors declare that they have no competing interests. 


\section{Availability of data}

Requests for the data must be made to The DHS Program at https://dhspr ogram.com/what-we-do/survey/survey-display-467.cfm.

\section{Consent for publication}

Not applicable.

\section{Ethics approval and consent to participate}

The 2011 DHS and 2015 IMASIDA protocols were approved by the ICF Institutional Review Board, the Mozambican National Bioethics Committee and the Office of the Associate Director for Science in the Center for Global Health at the Centers for Disease Control and Prevention. Prior to enrolment, all eligible participants from both surveys provided written informed consent to participate. The consent was obtained from the mother or guardian of a child. The data were collected anonymously [36].

\section{Funding}

Not applicable.

\section{Publisher's Note}

Springer Nature remains neutral with regard to jurisdictional claims in published maps and institutional affiliations.

Received: 2 October 2018 Accepted: 28 March 2019

Published online: 02 April 2019

\section{References}

1. WHO. World malaria report. Geneva: World Health Organization; 2017.

2. INE. Mortality in Mozambique: results from a 2007-2008 post-census mortality survey. Mozambique. 2012.

3. MISAU. Inquérito de Indicadores de Imunização, Malária e HIV/SIDA em Moçambique (IMASIDA) 2015 - Relatório Final. Mozambique. 2018.

4. Malik EM, Hanafi K, Ali SH, Ahmed ES, Mohamed KA. Treatment-seeking behaviour for malaria in children under five years of age: implication for home management in rural areas with high seasonal transmission in Sudan. Malar J. 2006;5:60

5. Sumba PO, Wong SL, Kanara HK, Johnson KA, John CC. Malaria treatmentseeking behaviour and recovery from malaria in a highland area of Kenya. Malar J. 2008;7:245.

6. Deressa W. Treatment-seeking behaviour for febrile illness in an area of seasonal malaria transmission in rural Ethiopia. Malar J. 2007;6:49.

7. Birhanu Z, Abebe L, Sudhakar M, Dissanayake G, Yihdego YY, Alemayehu $G$, et al. Malaria related perceptions, care seeking after onset of fever and anti-malarial drug use in malaria endemic settings of Southwest Ethiopia. PLoS ONE. 2016;11:e0160234.

8. Das A, Ravindran TS. Factors affecting treatment-seeking for febrile illness in a malaria endemic block in Boudh district, Orissa, India: policy implications for malaria control. Malar J. 2010;9:377.

9. Das A, Das Gupta RK, Friedman J, Pradhan MM, Mohapatra CC, Sandhibigraha D. Community perceptions on malaria and care-seeking practices in endemic Indian settings: policy implications for the malaria control programme. Malar J. 2013;12:39.

10. Getahun A, Deribe K, Deribew A. Determinants of delay in malaria treatment-seeking behaviour for under-five children in south-west Ethiopia: a case control study. Malar J. 2010;9:320.

11. Battle KE, Bisanzio D, Gibson HS, Bhatt S, Cameron E, Weiss DJ, et al. Treatment-seeking rates in malaria endemic countries. Malar J. 2016;15:20.

12. Awantang G, Babalola S, Koenker H, Fox K, Toso M, Lewicky N, et al. Correlates of social behaviour change communication on care-seeking behaviours for children with fever: an analysis of malaria household survey data from Liberia. Malar J. 2018;17:105.

13. MISAU and INE. Moçambique - Inquérito Demográfico e de Saúde 2011. Maputo: Instituto Nacional de Estatística; 2013.

14. PNCM. Plano Estratégico da Malária 2012-2016. Mozambique. 2012

15. INE. Censo 2017 Divulgação dos Resultados Preliminares. Mozambique. 2017.
16. Johansson EW, Gething PW, Hildenwall H, Mappin B, Petzold M, Peterson SS, et al. Diagnostic testing of pediatric fevers: meta-analysis of 13 national surveys assessing influences of malaria endemicity and source of care on test uptake for febrile children under five years. PLOS ONE. 2014;9:e95483.

17. Muhumuza G. Assessing factors influencing health seeking behavior for malaria treatment in children under five years in Rwimi Town Council Kabarole District. Int J Sch Cogn Psychol. 2015;2:151.

18. Xu JW, Xu QZ, Liu H, Zeng YR. Malaria treatment-seeking behaviour and related factors of Wa ethnic minority in Myanmar: a cross-sectional study. Malar J. 2012;11:417.

19. Romay-Barja M, Jarrin I, Ncogo P, Nseng G, Sagrado MJ, Santana-Morales MA, et al. Rural-urban differences in household treatment-seeking behaviour for suspected malaria in children at Bata District, Equatorial Guinea. PLOS ONE. 2015;10:e0135887.

20. Oberlander L, Elverdan B. Malaria in the United Republic of Tanzania: cultural considerations and health-seeking behaviour. Bull World Health Organ. 2000;78:1352-7.

21. Naing PA, Maung TM, Tripathy JP, Oo T, Wai KT, Thi A. Awareness of malaria and treatment-seeking behaviour among persons with acute undifferentiated fever in the endemic regions of Myanmar. Trop Med Health. 2017:45:31

22. Chaturvedi HK, Mahanta J, Pandey A. Treatment-seeking for febrile illness in north-east India: an epidemiological study in the malaria endemic zone. Malar J. 2009:8:301.

23. Klein $E Y$, Lewis IA, Jung C, Llinás M, Levin SA. Relationship between treatment-seeking behaviour and artemisinin drug quality in Ghana. Malar J. 2012;11:110.

24. Awuah RB, Asante PY, Sakyi L, Biney AAE, Kushitor MK, Agyei F, et al. Factors associated with treatment-seeking for malaria in urban poor communities in Accra, Ghana. Malar J. 2018;17:168.

25. US Embassy. Relatório de Liberdade Religiosa Internacional de Moçambique de 2016. https://mz.usembassy.gov/wp-content/uploads/sites /182/Mozambique-2016-International-Religious-Freedom-Report-PT.pdf. Accessed 12 July 2018.

26. PNCM. Plano Estratégico da Malária 2017-2022. Mozambique. 2017.

27. Smith LA, Bruce J, Gueye L, Helou A, Diallo R, Gueye B, et al. From fever to antimalarial: the treatment-seeking process in rural Senegal. Malar J. 2010;9:333.

28. Millar KR, McCutcheon J, Coakley EH, Brieger W, Ibrahim MA, Mohammed Z, et al. Patterns and predictors of malaria care-seeking, diagnostic testing, and artemisinin-based combination therapy for children under five with fever in Northern Nigeria: a cross-sectional study. Malar J. 2014;13:447.

29. Zacarias F. Relatório Final do Inquérito ao Orçamento Familiar - IOF2014/15. Mozambique. 2015.

30. Hamooya BM, Chongwe G, Dambe R, Halwiindi H. Treatment-seeking behaviour for childhood fever among caretakers of Chivuna and Magoye rural communities of Mazabuka District, Zambia: a longitudinal study. BMC Public Health. 2016;16:62.

31. Borah D, Sarma P. Treatment seeking behavior of people with malaria and households' expenditure incurred to it in a block in endemic area in Assam, North East India. BMC Infect Dis. 2012;12(Suppl 1):P41.

32. Salomão C. Avaliação da eficácia do sistema de distribuição de kits de malária para os Agentes Polivalentes Elementares em três províncias de Moçambique. Mozambique. 2018.

33. Chukwuocha UM, Okpanma AC, Chukwuocha AN, Nwakwuo GC. Social determinants of malaria treatment seeking time by mothers for children (0-5 years) in South Eastern Nigeria. J Trop Dis. 2015;2:154.

34. Romay-Barja M, Cano J, Ncogo P, Nseng G, Santana-Morales MA, Valladares $B$, et al. Determinants of delay in malaria care-seeking behaviour for children 15 years and under in Bata district, Equatorial Guinea. Malar J. 2016;15:187.

35. Thandar MM, Kyaw MP, Jimba M, Yasuoka J. Caregivers' treatment-seeking behaviour for children under age five in malaria-endemic areas of rural Myanmar: a cross-sectional study. Malar J. 2015;14:1.

36. DHS. Protecting the Privacy of DHS survey respondents. https://dhspr ogram.com/What-We-Do/Protecting-the-Privacy-of-DHS-Survey-Respo ndents.cfm. Accessed 17 May 2018. 